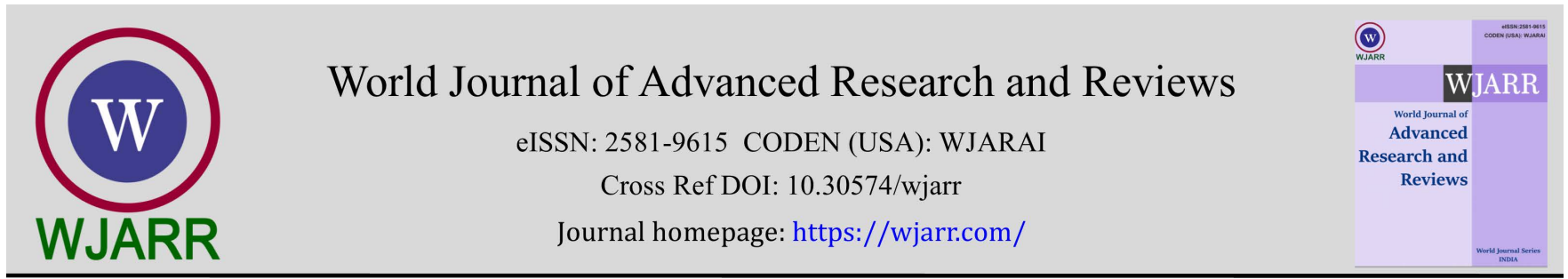

(RESEARCH ARTiCle)

\title{
Practices of waste management in health care facilities in Nepal's Biratnagar metropolitan city
}

\author{
Nawa Raj Subba * \\ Purbanchal University, Edenburgh International College, Biratnagar-16, Nepal.
}

World Journal of Advanced Research and Reviews, 2021, 12(03), 398-404

Publication history: Received on 18 November 2021; revised on 21 December 2021; accepted on 23 December 2021

Article DOI: https://doi.org/10.30574/wjarr.2021.12.3.0722

\begin{abstract}
Biratnagar is a medical referral centre with tertiary health care in Eastern Nepal. The city population is 202,061, according to the 2011 census. There are 35 Health Care Facilities (HCFs) in the city as of 2014. There are 7 HCFs, 2 nongovernmental HCFs, and 26 private HCFs. In 2014, the District Public Health Office Morang, the Biratnagar municipality, and the private sector collaborated to check Biratnagar's health care waste management. Investigators performed a semi-structured questionnaire and checklists while visiting health care sites. According to the survey results, $10 \%$ of HCFs use incinerators. $80 \%$ of HCFs separate their garbage, $60 \%$ use needle destroyer machines, and $50 \%$ use coloured dustbins to separate different sorts of medical waste. The bed occupancy rate is $78 \%$. Every day, one sweeper looks for 6.66 beds. Even $10 \%$ of HCFs let their waste out in the open. HCFs do not have enough capacity for waste disposal facilities. Thus, HCFs pay the municipality Rs. 1500- 15000 a month to have the facility's waste removed. In the municipality tractor, they are hauling medical garbage and home rubbish. As a result, the city discharges health care waste with household waste in the Singhiaya River. These actions endanger public health. Biratnagar city generates 118 Kgs of hazardous health care waste daily, necessitating immediate treatment. Biratnagar Municipality should collaborate with partners to develop a short and long-term strategy.
\end{abstract}

Keywords: Health Care Facility Waste Management; Public Health Hazards; Biratnagar; Nepal

\section{Introduction}

The Stockholm Convention on Persistent Organic Pollutants is a worldwide treaty signed in 2001 to safeguard human health and the environment against persistent organic pollutants [1]. According to the Tort law and principle, any organization that creates trash must dispose of the waste safely [2]. As a result, the HCF has the most significant responsibility for waste container traffic, on-site and off-site handling, treatment, and disposal. In addition, the Conference of the Parties to the Basel Convention on the Control of Transboundary Movements of Hazardous Waste and their Disposal developed Technical Guidelines on Environmentally Sound Management of Biomedical and Health Care Waste [3].

Nepal has the Solid Waste Management Act 2011, which provides a law foundation and guidance for Health Care Waste Management (HCWM). The primary goals of the acts are to do systematic and effective solid waste management by limiting solid waste at the source, reusing, processing, or disposing of solid waste. It also aims to keep the environment clean and healthy by reducing the negative impacts of solid waste on public health and the ecosystem [4].

Nepal Government enacted the Town Development Act of 1989 to give essential services and facilities to town inhabitants by reconstructing, enlarging, and developing existing towns, establishing new towns, and preserving the general public's health, convenience, and economic interest [5]. Furthermore, the Local Self-Governance Act of 1999

\footnotetext{
* Corresponding author: Nawa Raj Subba

Purbanchal University, Edenburgh International College, Biratnagar-16, Nepal.
} 
empowers the local council to punish anyone up to Rs. 15,000 for careless solid waste disposal [6]. Moreover, Nepal enacted the Environmental Protection Act of 1997 and the Environmental Protection Rules of 1997 to prevent the adverse effects of environmental deterioration on humans and ensure the correct use of natural resources for ecological conservation [7]. In addition, the government developed Solid Waste Management Policy 1996 to manage solid waste [8].

Nepal has had a government policy to deal with garbage and hospital waste for nearly two decades. For example, the metropolis created Biratnagar's Garbage Management Directive 2068 to address garbage management in the city [9]. Similarly, the Government of Nepal formulated National Sanitation Master Plan 2068 to improve the country's sanitation situation [10].

The Ministry of Health and Population has developed plans for private and non-governmental health facilities' formation, operation, policy, standards, and infrastructure guidelines 2061, focusing on hospital waste [11]. In addition, Nepal Health Research Council provided the Waste Management Guideline-2002 to National Health Services [12]. Furthermore, the Nepalese government has produced environmental and public health assessment studies to make the rubbish more environmentally and public health-friendly. In addition, the National Research Council and the World Health Organization have standards and information available in Nepal [13].

Ministry of Health and Population Nepal has formulated guidelines 2014 for Health Care Facility Waste Management (HCFWM) [14]. Health Care Waste Management Guideline. Ministry of Health and Population, Nepal. The Health Care Facility (HCF) shall comply with procedures to ensure proper HCWM, i.e., proper classification, segregation, collection, transportation, treatment, and disposal. The HCWM plan options are primarily dependent on the local situation. Locally accessible technology and maintenance are other significant factors to consider when developing an HCWM strategy. Therefore, HCF should adopt the HCWM strategy from the beginning of the HCF planning process. As a result, each HCF must create its HCWM Plan.

MoHP's guidelines 2014 have designated HCF administration as crucial for HCF waste management. HCF Administration forms a Health Care Waste Management Committee (HCWMC) and develops a written plan for waste management. It also designates a waste management officer to supervise and coordinate the waste management plan. Administration ensures that employees receive proper training and creates a positive working environment. Implementation, monitoring, and coordination are all handled by the HCF administration. The administration can make changes to the updated plan [14].

Let us now turn our attention to the subject's core object. We can divide HCW into two categories: Non-risk Health Care Waste and Health Care Waste that requires particular attention. According to studies, Non-risk HCWs account for roughly $75 \%$ to $90 \%$ of HCWs created by HCFs. We can split Non-risk HCWs into three types: (1). (a) Recyclable HCWs (plastics, metal, cans, glass, and so on); (b) Biodegradable HCWs (left food scraps or gardens, and so on); (c) Other nonrisk HCW (all the non-risk materials other than recyclable and biodegradable). Likewise, there are Health-risk HCWs (a) Infectious and highly infectious waste, (b) Other hazardous waste, and (c) Radioactive waste [3].

Biomedical hazardous HCWs require specific disposal consideration and contain five forms of waste: human anatomical waste, sharp waste, pharmaceutical waste, cytotoxic pharmaceutical waste, and blood and bodily fluids. The percentage of HCFs waste that requires special attention ranges from $10 \%$ to $25 \%$. However, according to WHO technical guidance, HCFs waste is roughly $20 \%$ hazardous and $80 \%$ ordinary waste [15].

Biratnagar is the capital of Nepal's Eastern region and the country's Province-1. The Terai has a greater population density. By road and air, Biratnagar connects to the Terai and hilly areas. People from the Terai, hilly, and mountainous regions travel here for treatment, despite the city's population of 202,061 according to the 2011 census. In addition, many people from India and Bangladesh travel to Biratnagar to treat their eyes. As a result, HCFs in Biratnagar care for inhabitants, patients from the Eastern Districts, and international visitors. As a result, Biratnagar's waste management problem is becoming more critical.

Based on the above, this study investigated the Waste Management methods used by Biratnagar city's Health Care Facilities.

\section{Material and methods}

When this writer was an officer in the Morang District Public Health Office in 2014, he initiated an investigation of HCFs waste in Biratnagar city. The assessment team consisted of three health workers. On behalf of the District Public Office, 
the researcher coordinated the team. The remaining two members were a metropolis public health officer and a privatesector public health officer.

At random, the investigator team visited ten different HCFs. They completed checklists and conducted interviews with HCFs administrators. They also observe the waste disposal system in the HCFs using a semi-structured questionnaire for discussion and a list for observation and meetings while collecting data. The study used Excel software for data analysis.

\section{Findings}

\subsection{Human resources for HCFs administration}

Table 1 Human resources in health facilities

\begin{tabular}{|l|c|c|c|c|}
\hline Health care facility & No of beds & Technical & Admin & Sweeper \\
\hline HCF1 & 15 & 20 & 10 & 5 \\
\hline HCF2 & 15 & 15 & 7 & 9 \\
\hline HCF3 & 15 & 13 & 4 & 3 \\
\hline HCF4 & 10 & 30 & 22 & 6 \\
\hline HCF5 & 15 & 14 & 6 & 4 \\
\hline HCF6 & 50 & 79 & 41 & 4 \\
\hline HCF7 & 15 & 12 & 5 & 2 \\
\hline HCF8 & 15 & 6 & 2 & 1 \\
\hline HCF9 & 100 & 132 & 118 & 8 \\
\hline HCF10 & 50 & 10 & 5 & 3 \\
\hline Total & 300 & 331 & 220 & 45 \\
\hline
\end{tabular}

Table 1 shows the status of the HCFs. There were technical 331, administrations 220, and sweepers 45 human resources to look after 300 beds in HCFs. In addition, there was one sweeper available for 6.66 beds.

\subsection{Bed occupancy and waste generation}

Table 2 Production of wastes products from Health Care Facilities

\begin{tabular}{|l|c|c|c|}
\hline Health care facility & No of beds & Bed occupied & Waste products Kg/day \\
\hline HCF1 & 15 & 13 & 3 \\
\hline HCF2 & 15 & 20 & 4 \\
\hline HCF3 & 15 & 15 & 15 \\
\hline HCF4 & 10 & 10 & 4 \\
\hline HCF5 & 15 & 7 & 4 \\
\hline HCF6 & 50 & 43 & 15 \\
\hline HCF7 & 15 & 8 & 5 \\
\hline HCF8 & 15 & 8 & 60 \\
\hline HCF9 & 100 & 60 & 50 \\
\hline HCF10 & 50 & 50 & 168 \\
\hline Total & 300 & 234 & \\
\hline
\end{tabular}


Table 2 depicts the bed occupancy rate and waste generated by HCFs. There are 300 beds in 10 HCFs, with patients occupying 234 of them. As a result, the bed occupancy rate is 78\%. That produced a total of $168 \mathrm{Kg}$ waste products per day. It indicates each bed generates $0.56 \mathrm{Kg}$ waste per day, and each Health Care Facility made $16.8 \mathrm{Kg}$ wastes per day.

\subsection{Category of Wastes}

At a rate of $16.8 \mathrm{~kg}$ per day in the sample of $10 \mathrm{HCFs}, 35 \mathrm{HCFs}$ generate 588 kilograms of waste each day in Biratnagar. According to the WHO guidelines [15], Biratnagar generates 470 kilograms daily of non-hazardous trash. Similarly, HCFs in the city produce 118 kilograms of hazardous waste daily. Public Health is concerned about 118 Kgs of dangerous waste created daily by HCFs. We must regulate it appropriately.

\subsection{Health Care Waste Management practices}

Table 3 Methods of waste management

\begin{tabular}{|l|c|c|}
\hline Methods & Frequency & Percentage \\
\hline Through city waste contractor & 9 & 9 \\
\hline Open dumping & 1 & 1 \\
\hline Use of segregation of wastes & 8 & 80 \\
\hline Use of needle destroyer & 6 & 60 \\
\hline Use of separate coloured dustbin & 5 & 50 \\
\hline Use of incinerator & 1 & 10 \\
\hline
\end{tabular}

Table 3 illustrates the waste management practices used by HCFs in Biratnagar. Enumerators noted 9 of 10 healthcare facilities use metropolis waste management contractors for their HCFs wastes. One health facility used an open dumping method to manage wastes of their Health Care Facility. HCFs separate their waste in $80 \%$ of instances, use needle destroyer machines in $60 \%$ of scenarios, and use coloured dustbins in $50 \%$ of situations to separate different types of medical waste. None of them has their disposal system.

\subsection{Waste management cost-sharing}

HCFs are paying Biratnagar metropolitan at Rs. 1500 to 15,000 per month for collecting wastes from their facilities. The municipality has managed this job by appointing a local Non-Government Organization, 'Swasthya Shantika Lagi Vatabaran Nepal' on a tender basis.

The health institution should manage the waste according to the norms, rules, and regulations [1, 2, 14]. However, there is a lack of space for waste management in the HCFs to set up a hospital in Biratnagar. It does not seem that these HCFs can manage wastes properly. The local government must work with the metropolitan government to manage hazardous waste. Biratnagar's HCFs have expressed interest in cost-sharing. They are also making payments to the local government. Metropolis should manage HCFs Hazardous waste in organized methods as soon as possible.

\subsection{Working Environment}

The HCFs have not formed the HCWMC committee in line with the guidance. On the other hand, the HCFs administration has cleaned the facility without any plan and training. Health facilities located on the roadsides were lack of space to manage waste. So, they said they were ready to pay the metropolis for waste management.

On the other hand, sweeping metropolis crews were found untrained and unaware of the dangers of handling medical waste. They gathered HCFs hazardous waste from the various coloured containers in one place. Sweepers were not wearing any masks or gloves while performing their duties. While some sweepers wear boots, the majority of them wear slippers. They collect leftovers and household debris and dispose of medical waste near the Singhiya River, an open place. 


\section{Discussion}

Based on a random sample of 10 HCFs in Biratnagar, the survey found 331 technicians for 300 beds, 220 administrative employees, and 45 sanitation staff. A cleaner cleans an average of 6.66 beds when it comes to sanitation. 45 cleaners in 10 HCFs equate fewer than five cleaners in a single health facility. In a 24-hour service organization, this number appears insufficient.

In the 10 HCFs studied, there were 300 beds. Patients have occupied 243 beds. On this basis, the bed occupancy rate is $78 \%$. On average, each HCF generates $16.8 \mathrm{~kg}$ of waste. The municipality collects roughly $588 \mathrm{~kg}$ of wastes from $35 \mathrm{HCF}$ every day. The survey discovered waste generation per bed in Biratnage is 0.56 kilograms. In Pokhara's several hospitals, the average waste generation per bed was $1.22 \mathrm{~kg}$ [16]. A study estimates, Nepal's overall HCFs waste be $0.533 \mathrm{~kg}$ per bed day. In the study, general, non-hazardous, and non-biodegradable trash accounts for $0.256 \mathrm{~kg} / \mathrm{bed}-$ day. In contrast, biodegradable waste accounts for $0.147 \mathrm{~kg} / \mathrm{bed}$-day, infectious waste, including sharps, accounts for $0.120 \mathrm{~kg} / \mathrm{bed}$-day, and hazardous chemical/pharmaceutical waste accounts for $0.009 \mathrm{~kg} / \mathrm{bed}$-day [17].

A study provides information on Nepal's HCFs waste management situation [18]. According to that survey, $70 \%$ of the incinerators in Nepal were not operational due to a lack of skilled human resources, spare parts, high fuel consumption, cultural and public opposition, and a lack of management commitment. This survey also noted that no health institution formed the HCWMC in Biratnagar city. Koshi zonal hospital has installed an incinerator plant in its compound. Still, the hospital did not use it due to high fuel consumption and spare parts. The Koshi zonal hospital was responsible for its waste management. However, residents in the adjacent town complain about the incinerator and waste emitting nasty odours and smoke.

No health facilities in Biratnagar have a proper waste disposal system. They relied on the metropolis's waste collection system. Urban carriers collect both wastes from households and HCFs on the way. 90\% HCFs were paying the city, and one was openly dumping its waste. However, $80 \%$ of HCFs segregate their garbage. $60 \%$ of HCFs destroyed their used needles in the facility. $50 \%$ of the HCFs provided coloured plastic garbage containers. Metropolis sweepers did not use masks or gloves properly when collecting and disposing of HCFs waste. Only $10 \%$ of HCFs use incinerators.

According to a survey [19], 90.32\% of HCFs do not use a proper waste treatment system, $61.29 \%$ of HCFs have extremely poor source separation, and $6.45 \%$ of HCFs do not use such guidelines. Among these, $80.65 \%$ do not practice acceptable and separate waste collection, and $67.42 \%$ have extremely poor transportation.

According to a study [18], most HCFs in Nepal, both at the district and sub-district levels, manage their solid waste using inefficient disposal methods such as drum incinerators, pit burning, earthen pit disposal, and open burning. Furthermore, research revealed that many institutions dump or throw waste in the back yard, ditches, rivers, open fields, hospital building corners, nearby ponds, or anywhere else on the property. The study shows that almost $60 \%$ of large HCFs in the different districts use municipal waste disposal systems in Nepal. However, $90 \%$ of HCFs in Biratnagar use the metropolis waste disposal system. As a result, Biratnagar's HCFs waste management is worse than the national average. Biratnagar's HCFs are also in the same lousy shape for waste disposal.

Even after an extended period, the Health Care Facility Waste Management scenario in Biratnagar has not improved. During this time, Biratnagar metropolitan received newly elected representatives and established local government. However, there has been no qualitative improvement in HCFs waste management, nor has any improvement in sanitation. We squandered this opportunity. The Election Commission of Nepal has scheduled another local election for the near future. The data presented is expected to use for the improvement of the city. Improper HCW management in HCFs is primarily responsible for the hazardous wastes produced. Thus, proper management of infectious and dangerous debris, i.e., adequate minimization, segregation, storage, transportation, treatment, and disposal, will considerably decrease the dangers to public health [14]. However, Nepal has updated the National Health Care Waste Management Standards and Operating Procedures-2020 [20].

Let's take a look at a city in a neighbouring province as an example. It is guiding us in some way. Birgunj While keeping public health in mind, Metropolitan City has successfully managed HCFs waste. The city has started collecting HCFs waste from the city's facilities and destroying it using modern technology, including human organs, contaminants used in therapy, and other items [21]. By this contemporary method, the metropolitan city commissioned a new plant at the cost of Rs. 62.2 million as part of the city's public welfare initiative (Mandal, 2021). The country's province-2, Birgunj Metropolis, has made significant progress in public health. 


\section{Conclusion}

As per Biratnagar's Health Care Facilities assessment, 10\% of HCFs utilize incinerators. 80\% of HCFs segregate their garbage, $60 \%$ operate needle destroyer machines, and $50 \%$ use coloured waste bins. The bed occupancy rate is $78 \%$. In a single day, one sweeper is responsible for 6.66 beds. In HCFs, there is no proper waste disposal infrastructure. Thus, HCFs use municipal carriers. For that, they pay the Biratnagar metropolis Rs. 1,500.00- Rs. 15,000.00 a month to have their waste serviced.

On the other hand, the Metropolitan has made no efforts to properly manage the city's HCF hazardous waste. The metropolitan cleaners do not care when handling and disposing dangerous medical waste. Instead, they are publicly transporting HCFs and household rubbish in a tractor. As a result, urban carriers dumped HCFs and household garbage in Biratnagar's adjoining Singhiya River. Furthermore, 10\% of HCFs leave their HCFs waste out in the open. These behaviours are hazardous to public health. Biratnagar's inadequate medical waste disposal infrastructure has a public health risk for an extended period.

In Biratnagar, 118 Kgs of health care waste daily need specific treatment measures urgently. Biratnagar Municipality should work with partners to do this. The Koshi Zonal Hospital's incinerator is a temporary option that can run through cost-sharing. However, in the long run, the municipality should work under the partnership idea by building a safe, contemporary disposal system that does not impact the human population.

\section{Recommendations}

Biratnagar city has a waste management policy and plans in place. However, the metropolis does not follow guidelines properly. These rules and activities are even outdated on a metropolitan city level. In recent years, there has been an increase in large HCFs. The metropolis should update the strategy and the program to address emerging health hazards from HCFs.

According to a directive from Nepal's Ministry of Health, the HCFs would be responsible for its waste management by forming the HCWMC. In Biratnagar, HCFs that opened like shops did not meet the requirements. Due to a shortage of space, the city HCFs are unlikely to handle the waste independently in the future. The Birgunj Municipality recently implemented a scheme to collect and dispose of HCFs waste in one location properly. In Biratnagar, the metropolis must play a coordinating role in managing HCFs waste. HCFs and the Biratnagar Metropolitan city are late to properly work for HCFs waste management. The Biratnagar city can improve its waste management system through short-term and long-term plans.

\section{Compliance with ethical standards}

\section{Acknowledgements}

For their contributions throughout the survey, I thank team members Dashi Lal Majhi from Biratnagar metropolitan and Bipulendra Jha from LifeGuard Hospital Biratnagar.

\section{References}

[1] UNEP. The Stockholm Convention on Persistent Organic Pollutants. Geneva. Secretariat of the Stockholm Convention on Persistent. 2001.

[2] Underwood, J. Tort Law: Principle in Practice. 2nd ed. Wolters Kluwer. 2018.

[3] UNEP/SBC/WHO. Preparation of National Health-Care Waste Management Plans in Sub-Saharan Countries; Guidance Manual. Secretariat of the Basel Convention and World Health Organization. 2004.

[4] NLC. Solid Waste Management Act- 2011. Nepal Law Commission, Kathmandu, Nepal. 2011.

[5] NLC. Town Development Act- 1989. Nepal Law Commission, Kathmandu, Nepal. 1989.

[6] NLC. Local Self-Governance Act- 1999. Nepal Law Commission, Kathmandu, Nepal. 1999.

[7] NLC. Environmental Protection Act of 1997 and the Environmental Protection Rules. 1997.

[8] MoLD. Solid Waste Management National Policy 2053. His majesty's Government's Ministry of Local Development, Pulchowk, Lalitpur. 1996. 
[9] Biratnagar Sub-metropolitan. Waste generation, collection, and disposal guidelines for Biratnagar Submetropolitan. 2068.

[10] NPC. National Sanitation Master Plan- 2068. Government of Nepal. National Planning Commission, Government of Nepal. 2068.

[11] MoHP. National Standards and Guidelines for Non-governmental and Private Hospitals Establishment, Operational Policy, Standards, Infrastructure requirements, Ministry of Health and Population. 2061.

[12] NHRC. National Health Care Waste Management Guidelines, Nepal Health Research Council. 2002.

[13] NHRC. National Environmental Health Impact Assessment Guidelines for Development Projects-2002. Nepal Health Research Council and World Health Organization. 2002.

[14] MoHP. Health Care Waste Management Guideline. Ministry of Health and Population, Nepal. 2014.

[15] WHO. Safe management of wastes from healthcare activities. Geneva, World Health Organization. 1999.

[16] Enayetullah I, Sinha A, Kabir SM, Rahman MM, Yesmin F. Feasibility Study for the Establishment and Operation of Common/Central Treatment Facility (CTF) for Hospital in Pokhara City. Under PPP Arrangement, Waste Concern Consultants, Dhaka, Bangladesh. 2011.

[17] UNEP. Compendium of Technologies for Treatment/Destruction of Health care waste, United Nations. 2012.

[18] Bhatta J. Healthcare Waste Management in Nepal and an Effort for Improvement at Resource-Poor Settings. March 2013.

[19] CEPHED. Environmental Health Condition of Hospitals in Nepal. 2012.

[20] MoHP. National Health Care Waste Management Standards and Operating Procedures-2020. Ministry of Health and Population, Nepal. 2020.

[21] Mandal R. Machine bata Phohor Nasta Garne Green Hospital Management Centre Udhghatan. DeshSanchar. December 2021. 